Review Article

\title{
Static Technique of Facial Reanimation: Review of Literature
}

\author{
Anjan Kumar Sahoo
}

Assistant Professor, ENT, Maulana Azad Medical College, New Delhi, India.

DOI: https://doi.org/10.24321/2349.7181.202013

I $\quad \mathbf{N} \quad \mathbf{F} \quad \mathbf{O}$

E-mail Id:

anjanvssmc@gmail.com

Orcid Id:

https://orcid.org/0000-0002-8073-6549

How to cite this article:

Sahoo AK. Static Technique of Facial Reanimation:

Review of Literature. J Adv Res Med 2020; 7(3):

13-15.

Date of Submission: 2020-11-29

Date of Acceptance: 2020-12-15
$\begin{array}{llllllll}\mathbf{A} & \mathbf{B} & \mathbf{S} & \mathbf{T} & \mathbf{R} & \mathbf{A} & \mathbf{C} & \mathbf{T}\end{array}$

Facial palsy and its complications are quit catastrophic. It affects the structural, functional and emotional aspects of an individual. The primary management of facial palsy should be supportive with surgery being always the second choice. Surgical management of facial palsy is challenging for the surgeons and to the patients. In this article, various surgical aspects of management of facial palsy with special emphasis on static technique of reanimation is discussed. Static facial reanimation is easy to perform and also it can be addressed to all the facial zones. Salient features of all the variety of static reanimation like fascial sling, brow correction, eye lid weight placement are described.

Keywords: Facial Palsy, Static Technique, Fascial Sling

\section{Introduction}

Surgery for facial palsy is one of the most challenging procedure because of its physical and psychological implication. One has to address both the static and dynamic functions of facial nerve. At the same time, one should also take care of the speech, oral incontinence, poor social connection, repeated biting of buccal mucosa and last but not the least the overall confidence of the patient. The incidence of facial palsy is around 30 cases per 1 lakh population per year. ${ }^{1}$ Bell's palsy is the most common cause of facial palsy in adults. Most of the patients recover completely from Bell's palsy except few. Various options are there to treat the above physical and functional limitation of facial nerve dysfunction. Years after year, we are unfolding the various managements of facial palsy. Before going for management, one should have the proper perception of facial nerve anatomy and its course. When there is injury to the facial nerve, timely juxtaposition of nerve will give rise to the best results. Other options like interposition nerve grafting, cable grafting and also various static procedures can also be considered (Table-1) $)^{2-5}$ For a better understanding, surgical treatment is mostly divided into dynamic and static type on the basis of reconstruction. Dynamic reconstruction helps in rehabilitation of various facial movements but static reconstruction only maintains the symmetry and function. Obviously, the best option is the dynamic one but, in certain difficult situations, the only option avail may be the static reconstruction. In this review, various static modalities of facial nerve treatment are highlighted.

Before making a choice for surgery, the surgeon should take into account the age of the patients, medical history, segment of nerve injured, duration of facial paralysis and most important the expectation of patient.

There are vast array of causes for facial palsy like congenital, neurologic, infectious, traumatic, iatrogenic, neoplastic, systemic, toxic and idiopathic. Irrespective of the causes, the management of facial palsy requires a dedicated multidisciplinary team of doctors. 


\section{Various Surgical options for Facial Palsy}

Table I

\author{
Acute Facial Paralysis ( $<3$ weeks) ${ }^{2,3}$ \\ - Facial nerve decompression \\ Transmastoid approach \\ Middle fossa approach, and \\ Translabyrinthine approach \\ - Tension-free primary facial nerve repair \\ - Cable grafting using \\ - Great auricular nerve, \\ Sural nerve, \\ - Medial and lateral antebrachial cutaneous nerves
}

Intermediate duration facial paralysis (3 weeks-2

years) 4

- Nerve transfers

Hypoglossal (most common)

Spinal accessory,

Masseteric branch of the trigeminal nerve

Motor branches of the cervical plexus

- Cross-facial nerve grafting

* If the contralateral facial nerve is intact and functional

\section{Chronic facial paralysis of $>\mathbf{2}$-year duration ${ }^{5}$}

- Muscle transfer techniques

- $\quad$ Regional muscle transfer e.g. temporalis muscle(most common) ,masseter , digastric

- Free muscle transfer e.g. gracilis, pectoralis minor, serratus anterior, and latissimus dorsi.

- Static techniques of facial reanimation

Can be used in all stages of facial palsy either as a temporary or a permanent measure

\section{Static Techniques of Facial Reanimation}

Can be used in all stages of facial palsy either as a temporary or a permanent measure. Static technique of facial reanimation (Table-2) is mostly used for chronic or intermediate facial palsy, where there is atrophy of muscle. Static technique address all zones of the face in contrast to dynamic method. It can also be combined with dynamic procedure to provide symmetry in immediate postoperative period.

\section{Static Techniques of Facial Reanimation}

Table 2

\section{- Static facial Suspension}

- Fascial sling suspension via allograft or autograft,

- Brow Ptosis correction ${ }^{6}$

- Direct brow lift

* Trans-blepharoplasty eyebrow lift

* Trans-forehead eyebrow/ forehead lift

- Endoscopic brow lift
Minimally invasive temporal brow lift

- Management of upper Eyelid

Lateral Tarsorrhaphy

Eyelid weight placement

Palpebral String Procedure

- Upper Eyelid Blepharoplasty

- Management of lower Eyelid

- Medial canthopexy

- Lateral tarsal strip procedure

- External nasal valve repair

\section{Static Facial Suspension}

The static slings are mostly brace around the zygomatic arch to the oral commissure and nasolabial fold. The advantages of static facial suspension are that the facial symmetry achieves at rest and also it prevents the dropping of mouth. A variety of autologous and alloplastic materials have been used for static facial suspension. The common autologous materials used for this are fascia lata and palmaris longus tendon. The fascia lata slings have the advantages of superior tensile strength and it also maintains its pre-surgical length. They are immunocompatible but may produce significant donor site morbidity. Polytetrafluroethylene (Gore-Tex, AlloDerm), polypropylene mesh are the common alloplastic materials used for static suspension. Granuloma formation, extrusion are the limitation of the alloplastic materials.

\section{Brow Ptosis Correction}

Old age patients having facial palsy generally requires the correction of brow ptosis. Addressing the brow is the most demanding and also gratifying to both the surgeons and the patient. Brow ptosis correction can be done by either direct or endoscopic method. Direct brow ptosis may be addressed by either trans-blepharoplasty eyebrow lift or trans-forehead eyebrow/forehead lift. ${ }^{6}$

\section{Trans-Blepharoplasty Eyebrow Lift}

It is suitable for relatively small degrees of brow ptosis affecting mainly the lateral two-thirds of the brow in any age group.

\section{Trans-Forehead Eyebrow/ Forehead Lift}

This method can be used for any degrees of brow ptosis. Since this correction produces a big scar, hence, male gender and persons having high fore head hair line are the preferred candidates for this method. The major drawbacks of this technique are the cosmetically disturbing scar, formation of granuloma around the braided suture lines, reduced sensation in the forehead and failure of the brow correction after sometime. ${ }^{7}$

\section{Management of Upper Eyelid}

Paralysis of the upper eyelids because of facial palsy leads 
to lagophthalmos, which results in incomplete closure of the lid, leading to corneal ulceration. Treatment of paralytic lagophthalmos should be done as early as possible in patients who have little chance of regression. ${ }^{8}$ When cosmesis is not the priority one may go for tarsorrhaphy to deal with the exposed cornea. Dealing with the situations, one may go either for the temporary or permanent tarsorrhaphy.

\section{Eyelid Weight Placement}

Upper eyelid gold and platinum weight implant is the most common and widely used static procedure for treatment of lagopthalmos. ${ }^{9}$ They were implanted into a small pocket between the orbicularis oculi and the tarsal plate of the upper eyelid, fitting the curvature of the eye. The weight should be placed at the superior border of the tarsus for a better cosmetic result as it is hidden by the normal sulcus of the upper eye lid. Usually the weight varies between 1.6 to $1.8 \mathrm{gm}$. Nowadays, platinum is preferred because of its better biocompatibility. Also, because of higher density of platinum the volume can be reduced by $10 \%$ in comparison to gold implants ${ }^{10}$.

\section{Advantages of Eyelid Weight Placement}

- Technically simple to perform

- Complete closure of the eyelid without limiting the visual field

- Produces good functional and cosmetic results

- Relatively low complication rate

- Can be combined with other surgical lid corrections procedure

- Reversible procedure

\section{Disadvantage}

- Allergic reactions

- Extrusion of implant

- Migration of implant

\section{External Nasal Valve Repair}

Because of paralysis of small muscle responsible for opening of the nostril, there is generally nasal obstruction on the paralysed side. It can be corrected by nasal valve suspension or traditional rhinoplasty methods.

\section{Conclusion}

Static technique of facial reanimation takes care of all the zones of face. It can be used either as a temporary or permanent method and also can be used in any duration of facial palsy. Most of the times, it is reversible and also technically simpler. Additionally, it can also be combined with dynamic mode of facial reanimation. Knowledge of various technique of static reanimation not only improves the confidence of surgeon but also adds to the overall final outcome of facial palsy surgery.

\section{Conflict of Interest: None \\ References}

1. Falco NA, Eriksson E. Facial nerve palsy in the newborn: incidence and outcome. Plast Reconstr Surg 1990; 85: 1-4.

2. Sofferman RA. Facial nerve injury and decompression. In: Nadol JB, Mckenna MJ, editors. Surgery of the Ear and Temporal Bone. Philadelphia (PA): Lippincott Williams and Wilkins; 2005. pp. 435-450.

3. Humphrey CD, Kriet JD. Nerve repair and cable grafting for facial paralysis. Facial Plast Surg 2008; 24: 170-176.

4. Tai CY, Mackinnon SE. Surgical options for facial reanimation. Mo Med 2006; 103: 270-274.

5. Mehta RP. Surgical treatment of facial paralysis. Clin Exp Otorhinolaryngol 2009; 2: 1-5.

6. Karimi N, Kashkouli MB, Sianati H, Khademi B. Techniques of Eyebrow Lifting: A Narrative Review. J Ophthalmic Vis Res 2020; 15(2): 218-235.

7. Tyers AG. Brow lift via the direct and transblepharoplasty approaches. Orbit 2006; 25(4): 261-265.

8. Yu Y, Sun J, Chen L, Liu L. Lid loading for treatment of paralytic lagophthalmos. Aesthetic Plast Surg 2011; 35(6): 1165-71.

9. Manodh P, Devadoss P, Kumar N. Gold weight implantation as a treatment measure for correction of paralytic lagophthalmos. Indian J Dent Res 2011; 22(1): 181.

10. Schrom T. Lidloading bei Fazialisparese [Lidloading in facial palsy]. Laryngorhinootologie 2007; 86(9): 634-638. 